\title{
The Effects of the Incentive System on Employees' Entrepreneurship and Innovation Performance: Moderating Effect of Locus Control focused on the Private Hospitals
}

\author{
Gandulam Ganbold ${ }^{1}$, Muhammad Ayaz ${ }^{2}$, Chen Shenfchen ${ }^{3}$, and Hyeongyu Jang ${ }^{4}$ \\ ${ }^{1,2,3}$ Ph.D. Candidate, Department of Business Administration, \\ Gyeongsang National University, Korea \\ ${ }^{4}$ Professor, Department of Business Administration, \\ Gyeongsang National University, Korea \\ ${ }^{1}$ gandi_0407@naver.com, ${ }^{2}$ mayaz5404@gmail.com, ${ }^{3}$ c1170336212@163.com, \\ ${ }^{4} j \mathrm{jmgt21} @ g n u . a c . k r$
}

\begin{abstract}
The development of new medical devices and medical services in the environment that has been changed by COVID-19 is indispensable for the improvement of public health. Therefore, this paper discusses how the concept of incentive systems and employees' entrepreneurship can be applied to achieve innovation performance within a hospital sector (hospital employees) in South Korea. The purpose of this study is to examine relationships among the incentive system, employees' entrepreneurship, and innovation performance (product innovation, process innovation). In addition, the study investigates the moderating effect of locus of control between all model paths. The result of the paper shows the positive effects of the incentive system on employees' entrepreneurship. Furthermore, employees' entrepreneurship has a significant influence on product innovation and process innovation. Finally, the moderating effect according to the locus of control was partially adopted.
\end{abstract}

Keywords: Incentive system, Employees' entrepreneurship, Innovation performance, Locus control, Private hospital

\section{Introduction}

Innovation in hospitals itself is scarcely a new problem. Knowledge and innovation in the area of health care are inextricable elements of universal human history. In particular, after the novel coronavirus infection (COVID-19), major changes are expected in the hospital environment and medical service delivery system. The process of solving these emerging problems and establishing a long-term infection response system, and the change of public perception through COVID19, are expected to be an opportunity for hospital innovation and medical system improvement in many areas. Therefore, in a rapidly changing life pattern and environment, organizations need to innovate and constantly create new customer value to survive and create competitive advantage and achieve sustainable growth. To this end, creative and innovative entrepreneurship that can use crisis as an opportunity is required [1]. Entrepreneurship means a creative innovation spirit that predicts future changes and challenges novelty, and there are differences in corporate performance depending on entrepreneurship. Entrepreneurship is an

Article history:

Received (March 21, 2021), Review Result (April 25, 2021), Accepted (July 10, 2021) 
important driver of innovation that will enable to provide market opportunities, provide new business opportunities, and create new products and processes [2]. However, it has been established that the entrepreneurship of employees is formed by external influence factors rather than by employees themselves, and one of the external factors is the incentive system provided by the organization. Any organization that does not have concern for workers' welfare tends to produce less and is vulnerable to failure. Every reward system is based on the assumption that rewarding employees would attract, retain and motivate workers [3]. Also, this study attempts to demonstrate the usefulness of personality in explaining human behavior in organizations and focuses on locus of control as it relates to behavior in organizational settings.

The purpose of this study aims to verify the influence relationship between the incentive system, the entrepreneurship of employees, and the organizational product and process innovation performance. In addition, the study investigates the moderating effect of locus of control between all model paths. Above all else, this study highlights its value and differentiation in that it focused on the incentive system in hospitals, a non-profit organization, and identified its sub-attributes, and that the entrepreneurial orientation of the hospital organization identified the relationship between product innovation and process innovation. In addition, it is also noteworthy that the possibility of practical application was maximized by discriminating all these relationships according to external and internal control tendencies

\section{Theoretical background}

\subsection{Incentive system and employees' entrepreneurship}

Herzberg (1959) proposed "Motivation-Hygiene Theory", also known as "Two Factors Theory." From this point of view, shaping satisfied employees has to make use of an appropriate incentive system. Hornsby et al. (2002) stress that an effective reward system that encourages corporate entrepreneurship must consider goals, feedback, emphasis on individual responsibility, and results-based incentives [4]. Based on related prior studies, the incentive system in the hospital sector is composed of variables such as monetary rewards, social rewards, and status rewards, to identify the effect of the incentive system on the entrepreneurship of employees [5]. First money reward is containing issues regarding salary programs wages, commission-based programs, and financial supports including discretionary bonuses [6]. Second, the status reward is that officially awards citations to excellent employees who have worked hard in the company. For example, there are good promotion systems according to work performance and good training compensation systems, as well as structures, increasing from job descriptions. [7]. Third, there is a social reward system that provides domestic and foreign training opportunities to outstanding employees who achieve the goals of the organization and provides paid leave for vacation or travel. In addition, medical insurance, medical examinations, and medical support systems, the convenience of work environment facilities are well established.

H1: The incentive system has a positive effect on the employees' entrepreneurship.

\subsection{Employees entrepreneurship and innovation performance}

Entrepreneurship and business venturing, at both individual and firm levels, are becoming an essential part of any innovation ecosystem. The company's corporate entrepreneurial activities directly affect its innovation performance [8]. Therefore, this study attempts to verify organizational innovation by dividing it into product innovation and process innovation based on previous research. First, in this study, in the case of hospitals, product innovation is defined 
as the degree of competitiveness of medical devices or the degree to which they are often updated with the latest medical equipment and technologies. Second, Process innovations are linked to changes in the way hospitals go about their work; that is, the introduction of new activities such as outpatient services, medical and social services for the destitute, and the development of networks with doctors in private practice and or voluntary organizations [9]. Based on the review of literature, this study presents the following hypothesis.

$\mathrm{H} 2$ : Employee entrepreneurship has a positive effect on product innovation.

H3: Employee entrepreneurship has a positive effect on process innovation.

H4: Product Innovation has a positive effect on process innovation.

\subsection{Locus of control}

Locus of control is a mental and social wisdom theory that brings up the extension to individuals' remark control over their lives and atmosphere [10]. On the other side, locus of control is a capacity that has relevant control in addition to outcomes. Those who consider themselves capable of controlling their consequences are known to have internal or possessing internal locus of control. Individuals with an external locus of control consider their conclusions away from their control [11]. The internal control trait means employees believe awards are subject to the results of their actions or property caused by themselves, which they can control. Externals control trait believed reward is controlled by other external forces, such as other people, fate, and opportunities, individuals cannot grasp [12]. Therefore, based on previous papers, this study presents the following hypothesis.

H5: Locus of control is the moderator role between all of the model paths (H5a, H5b. H5c, $\mathrm{H} 5 \mathrm{~d})$

\section{Research method}

\subsection{Research model and measures}

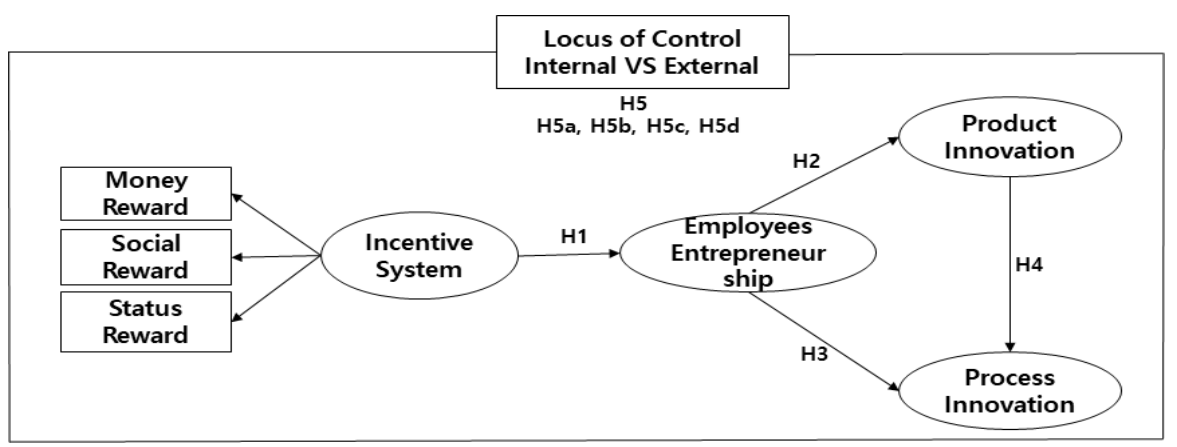

Figure 1. Research model

Measures: All the constructs were measured using five-point Likert-type scales anchored by "strongly disagree" and "strongly agree". The items of all constructs were adapted from previous existing scales. Ten items adapted from Jae-Young Yang et al [6] were used to measure the incentive system, and nine items adapted from Lim, Jung-Hee et al were used to measure entrepreneurship [13]. The three and three items adapted from Hameed et al [14] and Sok et al [15] were used to measure product innovation and process innovation performance respectively. Finally, three items were used to measure the locus of control adapted from Rotter [12]. 


\subsection{Research methodology}

The SPSS and AMOS statistics is a software package that was used to analyze the data. In this study, the survey was conducted 246 workers from the hospital sector in Jinju City, South Korea. The data were collected for 1 month from January 2021 to February 2021 by visit survey.

The main characteristics of the interviewees were, $211(85.8 \%)$ were from females and 35 $(14.2 \%)$ were from males. $76(30.9 \%)$ of the respondents were $20-29$ years old, $70(28.5 \%)$ of the respondents were between 30-39 years old, 66(26.8\%) of the respondents were between 4049 years old, and $34(13.8 \%)$ of the respondents were 50 years old or over. In addition, most of the respondents (a total of 154,62.6\%) were working in a department as a nurse or nurse's assistant. Moreover, the respondents' working periods were mainly less than 5 years 110 (44.7 $\%)$.

\section{Results}

\subsection{Reliability and confirmatory factor analysis}

The measurement model was evaluated, and convergent validity was assessed using loadings, average variance extracted (AVE), and composite reliability (CR). For models with goodness of fit to data: $\mathrm{CMIN}=335.321, \mathrm{CMIN} / \mathrm{df}=1.247, \mathrm{CFI}=.883, \mathrm{TLI}=.859, \mathrm{IFI}=.894$, $\mathrm{NFI}=.624, \mathrm{GFI}=.895, \mathrm{AGFI}=.863 \mathrm{RMR}=.051, \mathrm{RMSEA}=.044$. According to the analysis, $\mathrm{CR}$ values were found to be 0.7(0.748 0.952) and AVE values over 0.5(0.597 0.845) for all variables. Also, all of the AVE values for all under-study constructs were beyond the recommended values of 0.50 . Nevertheless, the seven-question items MR3, SCLR1, SCLR2, STSR3, EPSHIP7 were deleted based on a (0.50).

The reliability analysis result was Cronbach's coefficient $\alpha$ estimates for seven variables were more than .70, which was considered acceptable.

\subsubsection{Second-order confirmatory factor analysis}

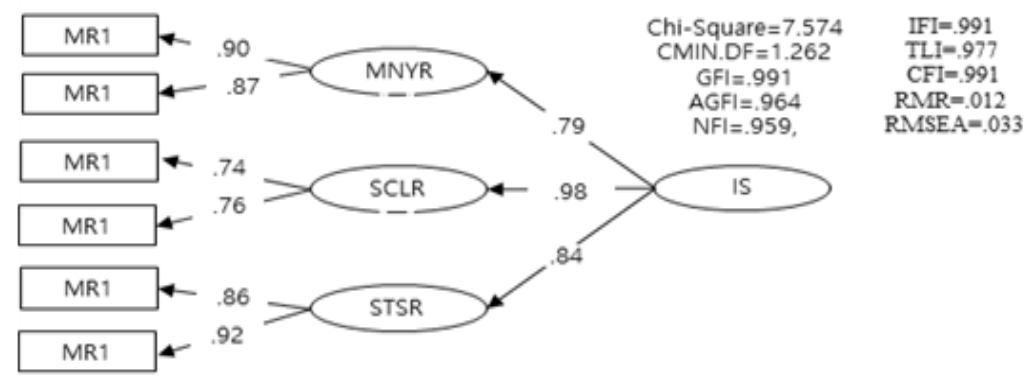

Figure 2. Result for second-order CFA

Abbreviation: MR= Money Reward, SCLR $=$ Social Reward, STSR= Status Reward, EPSHIP = Entrepreneurship, PRO IN=Product innovation, PRCS IN=Process innovation, L of Ctrl=Locus of control

\subsection{Correlation analysis}

The correlations among the variables were analyzed. As shown in [Table 1]. The comparison of AVE square root was higher than correlation. As a result of comparing the correlation of all 
two variables and the square root value of AVE, the correlation value is lower than the square root value of all AVEs. In addition, no pair of measures was found with a correlation that exceeds 0.9 , indicating no multi-collinearity exists among the constructs.

Table 1. Correlation analysis

\begin{tabular}{|c|c|c|c|c|c|c|c|}
\hline Question & MR & SCR & STSR & EPSHIP & PRO IN & PRCS IN & L of Ctrl \\
\hline MR & .791 & & & & & & \\
\hline SCR & .565 & .597 & & & & & \\
\hline STSR & .450 & .586 & .893 & & & & \\
\hline EPSHIP & .121 & .196 & .158 & .718 & & & \\
\hline PRO IN & .127 & .168 & .115 & .264 & .845 & & .728 \\
\hline PRCS IN & .115 & .187 & .132 & .392 & .732 & \\
\hline L of Ctrl & .019 & .044 & .030 & .331 & .157 & .201 & .771 \\
\hline
\end{tabular}

\subsection{Path analysis}

The results of the path analysis are shown in [Table 2]. The values of model fit indices chisquare $=200.453, \mathrm{D} / \mathrm{F}=156, \mathrm{p}=.000, \mathrm{GFI}=.918, \mathrm{AGFI}=.890, \mathrm{RMR}=.067, \mathrm{RMSEA}=.034$ is above the threshold values and indicates a good model fit. The hypothesis test results are as follows.

Table 2. Path analysis

\begin{tabular}{|c|c|c|c|c|c|}
\hline Hyp. & Relationship & Estimate & S.E. & C.R. & P-value \\
\hline H1 & Incentive System $\rightarrow$ Entrepreneurship & .470 & .087 & 5.507 & Supported $* * *$ \\
\hline H2 & Entrepreneurship $\rightarrow$ Product Innovation & .521 & .092 & 6.886 & Supported $* * *$ \\
\hline H3 & Entrepreneurship $\rightarrow$ Process Innovation & .270 & .051 & 4.435 & Supported $* * *$ \\
\hline H4 & Product Innovation $\rightarrow$ Process Innovation & .694 & .053 & 8.999 & Supported $* * *$ \\
\hline CMIN=200.453, df=156, CMIN/DF=1.285, GFI=.918, AGFI=.890, NFI=.699, IFI=.913, TLI=.886, CFI=.906, \\
RMR=.067, RMSEA=.034 \\
\hline
\end{tabular}

\subsection{Testing locus of control as a moderator}

To examine the differences according to the locus of control, a multi-group analysis was conducted by dividing into an internal control group $(\mathrm{n}=146)$ and an external control group $(\mathrm{n}$ $=100)$ based on the mean value (mean $=3.58)$. The result received partial support [Table 3].

Table 3. Multi-group analysis

\begin{tabular}{|c|c|c|c|c|c|c|}
\hline \multirow{2}{*}{ Hyp. } & \multirow{2}{*}{ Relationship } & $\begin{array}{c}\text { Internal } \\
\mathrm{N}=146\end{array}$ & $\begin{array}{c}\text { External } \\
\mathrm{N}=100\end{array}$ & $\begin{array}{c}\text { Free } \\
\text { Model }\end{array}$ & $\begin{array}{c}\text { Default } \\
\text { Model }\end{array}$ & \multirow{2}{*}{$\begin{array}{c}\Delta \chi^{2}(\Delta \mathrm{df}=1) \\
\text { Result }\end{array}$} \\
\cline { 3 - 4 } H5a & $\begin{array}{c}\text { Incentive System } \\
\rightarrow \text { Entrepreneurship }\end{array}$ & $.213(1.885)$ & $\mathbf{. 6 2 2} \mathbf{( 4 . 2 4 5 )}$ & & 444.938 & $3.147(.076) *$ \\
\cline { 1 - 3 } H5b & $\begin{array}{c}\text { Entrepreneurship } \\
\rightarrow \text { Product } \\
\text { Innovation }\end{array}$ & $.270(2.545)$ & $.447(3.203)$ & \multirow{2}{*}{441.792} & 441.879 & $.087(.768)$ \\
\hline H5c & $\begin{array}{c}\text { Entrepreneurship } \rightarrow \\
\text { Process Innovation }\end{array}$ & $.249(2.807)$ & $.144(1.358)$ & & 441.847 & $.055(.814)$ \\
\hline
\end{tabular}




\begin{tabular}{|c|c|c|c|c|c|c|}
\hline H5d & $\begin{array}{c}\text { Product Innovation } \\
\rightarrow \text { Process } \\
\text { Innovation }\end{array}$ & $.689(5.384)$ & $.757(4.959)$ & & 446.015 & $4.223(.040) * *$ \\
\hline
\end{tabular}

\section{Conclusion and discussion}

This study aimed to empirically identify the relationship between employee entrepreneurship and organization innovation performance of the incentive system for hospital staff in South Korea. In addition, the moderating effect according to the Locus of control was confirmed. The findings and implications are as follows.

First, it was found that the incentive system had a positive effect on the employees' entrepreneurship. In particular, the social reward was the most important factor in explaining the incentive system. The results of this study show that those employees want organizations with well-equipped medical insurance, regular health check-ups, and medical expenses support systems because of improved living standards and an aging population. It also shows that the organizational incentive system, which provides opportunities to improve competency through external education expenses support, overseas training, and internal education, has become more important. Next, the status reward is an important factor in shaping the entrepreneurship of employees. Therefore, it shows that hospitals providing a good promotion system based on employee's performance and giving all employees a chance to compete fairly has a positive impact on their entrepreneurship. In addition to the financial bonus system according to work performance, encouraging employees in various aspects, such as family allowance and monthly rent, has a better effect on enhancing the entrepreneurship of employees.

Second, Employees' entrepreneurship appears to have a positive impact on hospital product innovation and process innovation. This result shows that the entrepreneurship of employees has a significant role in shaping organizational innovation performance, and shows the same results as previous studies that it forms an organizational innovation through entrepreneurship [16].

Third, Product innovation has a positive effect on process innovation, which was also supported. These results show that to achieve service innovation, product innovation must first be backed up. Especially for hospitals, new activities such as service innovation linked to changes in work progress, outpatient services, the introduction of new medical services, and the development of networks with private doctors will be possible only when medical facilities are equipped and creative and innovative ideas exist.

Finally, Hypothesis $5 \mathrm{~b}$ and $5 \mathrm{c}$ were rejected. Therefore, this shows that once entrepreneurship has been formed, the results of the organizational innovation performance resulting from entrepreneurship cannot be changed easily due to further external factors. Therefore, to maximize the innovation performance of hospitals, the most important thing is the process of forming entrepreneurship so that each employee can work in the position of the organization manager. However, since the incentive system within the organization plays an important role in the entrepreneurship of employees, providing an environment in which employees can further develop their capabilities, especially starting with social welfare incentives, is recommended.

On the other hand, hypothesis 5a was supported at the significance level of $10 \%$. Also, Hypothesis $5 \mathrm{~d}$ was supported. In other words, the impact of product innovation on process innovation appears to be greater when it is external control rather than internal control. It can be inferred that the case of making decisions based on external control power based on various information generally has a high capacity for coordinating decision-making according to the 
situation. However, it can be presumed that if the progressive tendency exerts an influence on process innovation, it puts a greater weight on the external control based on the ego rather than the external control based on external information.

However, there are still limitations that could be addressed in future research. This study and the model have been applied to two hospitals in the health sector in Jinju City, South Korea. Using data across different regions and multiple hospitals (university hospitals) would help to generalize stronger results. In addition, ethical issues have recently emerged, but this study did not consider these parts well.

\section{References}

[1] J. Y. Kim, "A study on the effect of technological entrepreneurship and network capability on technology innovation capability and innovative performance: Focused on technology-based start-ups," Soongshil University, doctoral dissertation, (2017)

[2] T. Bailetti, "Technology entrepreneurship: Overview, definition, and distinctive aspects," Journal of Technology Innovation Management Review, vol.2, no.2, pp.5-12, (2012)

[3] O. E. James, R. Ella, S. E. Nkamare, F. E. Lukpata, and S.L. Uwa, "Effect of reward system among health care workers performance: A case study of university of Calabar teaching hospital Calabar, "Nigeria, Journal of Hospital Administration, ,vol.12, no.3, pp.1267, (2015)

[4] J. S. Hornsby, D. F. Kuratko, and S. A Zahra, "Middle managers' perception of the internal environment for corporate entrepreneurship: Assessing a measurement scale," Journal of Business Venturing 17, pp.253-273, (2002)

[5] J. Y. Yang and Y. J. Park, "The effect of incentive systems on organizational loyalty, business performance, and corporate performance: A focus on resort employees," International Journal of Tourism and Hospitality Research, vol.34, no.1, pp.87-101, (2020)

[6] G. T. Nigusie and H. Getachew, "The effect of reward system on employee creativity," Journal of Higher Education Service Science and Management (JoHESSM), vol.2, no.1, (2019)

[7] T. Besley and M. Ghatak, "Status incentives," American Economic Review, vol.98, no.2, pp.206-11, (2008)

[8] W. C. Kim and R. Mauborgne, "Blue ocean strategy: From theory to practice," California Management Review, vol.47, no.3, pp.105-121, (2005)

[9] V. Anatole-Touzet and W. Souffir, "Innovation technologique, organisation du travail et gestion des compétences," Gestions hospitalières, no.354, pp.222-225, (1996)

[10] K. A. April, B. Dharani, and K. Peters, "Impact of locus of control expectancy on level of well-being," Rev. Eur. Stud., vol.4, no.124, (2012)

[11] I. H. Zaidi and M. N. Mohsin, "Locus of control in graduation students," International Journal of Psychological Research, vol.6, no.1, pp.15-20, (2013)

[12] J. B. Rotter, "Generalized expectancies for internal versus external control of reinforcements," Psychological Monographs, vol.80, no.1, pp.28, (1966)

[13] J. H. Lim, S. G. Kong, S. Y. Oh, "The effect of entrepreneurship on innovation and management performances: Focus on the 5-star hotels in Seoul," Journal of Hospitality and Tourism Studies, vol.21, no.4, pp.114-130, (2019)

[14] W. -U Hameed, A. Sabir, R. Saeed, S. Humanyon, and A. Asad, "The influence of behavioral biases on investment decision making: A moderating role of religiosity among Pakistani investors,” International Journal of Management Research and Emerging Sciences, vol.8, no.1, pp.87-98, (2018)

[15] P. Sok, A. O' Cass, “Achieving service quality through service innovation exploration-exploitation: The critical role of employee empowerment and slack resources," Journal of Services Marketing, vol.29, no.2, pp.137-149, (2015) 
[16] J. H. Lim, S. G. Kong, S. Y. Oh, "The effect of entrepreneurship on innovation and management performances: Focus on the 5-star hotels in Seoul," Journal of Hospitality and Tourism Studies, vol.21, no.4, pp.114-130, (2019)

\section{Authors}

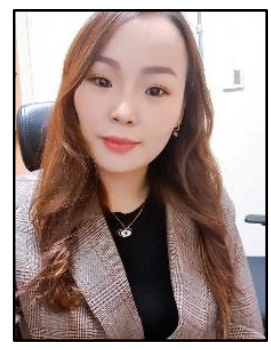

\section{Gandulam Ganbold}

Gyeongsang National University, South Korea.

Ph.D. Candidate, Department of Business Administration.

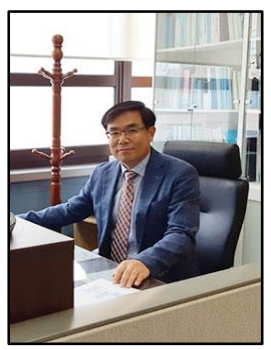

\section{Hyeongyu Jang}

Gyeongsang National University, South Korea.

Professor, Department of Business Administration.

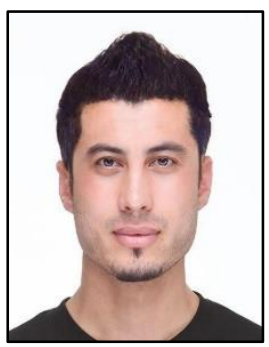

\section{Muhammad Ayaz}

Gyeongsang National University, South Korea.

Ph.D. Candidate, Department of Business Administration.

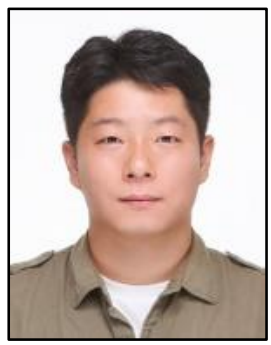

\section{Chen Shenfchen}

Gyeongsang National University, South Korea.

Ph.D. Candidate, Department of Business Administration. 